\title{
Food and health promotion literacy among employees with a low and medium level of education in the Netherlands
}

Hanne C. S. Sponselee ${ }^{1^{*}}$ (D), Willemieke Kroeze ${ }^{1,2}$, Maartje P. Poelman ${ }^{3}$, Carry M. Renders ${ }^{1}$, Kylie Ball ${ }^{4}$ and Ingrid H. M. Steenhuis ${ }^{1}$

\begin{abstract}
Background: Prior research indicates a positive association between socioeconomic position and health literacy levels. We hypothesize comparable socioeconomic gradients for food literacy. This study aims to determine the level of self-perceived food literacy and health promotion literacy among adults with a low and medium level of education and from various subgroups, as well as the association between these food and health literacy levels. Furthermore, this study aims to explore the associations of self-perceived food literacy (SPFL) and health promotion literacy (HPL) in BMI.

Methods: A cross-sectional study was conducted among employees with a low and medium level of education. Descriptive analyses were performed to compute SPFL and HPL levels. Analyses of variance were performed to test differences between subgroups. The correlation between SPFL and HPL was computed by Pearson's r. Multivariate linear regression analyses were used to explore 1) the association between SPFL and HPL adjusted for demographic characteristics 2) the associations between SPFL and HPL in BMI.

Results: The majority (63.1\%) of all participants ( $n=222$ ) scored low on SPFL and 34.5\% scored inadequate or problematic on HPL. No significant educational or weight-status differences were found in SPFL or HPL levels. On most levels, women compared to men and older compared to younger employees scored significantly higher. A small positive correlation between the two mean levels was found, $r=.25, P<.001(n=203)$. Multivariate linear regression analyses showed a significant association between SPFL and HPL ( $B=.31,95 \% \mathrm{Cl}=.15-.48)$. No significant associations between SPFL and HPL in BMI were found.

Conclusions: This study suggests there is room for improvement in SPFL and HPL among adults with a low and medium level of education. Future research should consider comparing low and middle socioeconomic with high socioeconomic groups when exploring food and health literacy. Regarding health promotion activities for adults with a low and medium level of education, it is recommended to focus on improving both food and health literacy. Furthermore, more research is needed to explore direct proxies of weight-status to better understand the role of food and health literacy in overweight patterns.
\end{abstract}

Keywords: Food literacy, Self-perceived food literacy, Health literacy, Health promotion literacy, Level of education, Workplace, Prevention, Socioeconomic health inequities

\footnotetext{
* Correspondence: h.c.s.sponselee@vu.nl

'Department of Health Sciences, Faculty of Sciences, VU University Amsterdam and Amsterdam Public Health Research Institute, $1081 \mathrm{HV}$ Amsterdam, Netherlands

Full list of author information is available at the end of the article
}

C C The Author(s). 2021 Open Access This article is licensed under a Creative Commons Attribution 4.0 International License, which permits use, sharing, adaptation, distribution and reproduction in any medium or format, as long as you give appropriate credit to the original author(s) and the source, provide a link to the Creative Commons licence, and indicate if changes were made. The images or other third party material in this article are included in the article's Creative Commons licence, unless indicated otherwise in a credit line to the material. If material is not included in the article's Creative Commons licence and your intended use is not permitted by statutory regulation or exceeds the permitted use, you will need to obtain permission directly from the copyright holder. To view a copy of this licence, visit http://creativecommons.org/licenses/by/4.0/ The Creative Commons Public Domain Dedication waiver (http://creativecommons.org/publicdomain/zero/1.0/) applies to the data made available in this article, unless otherwise stated in a credit line to the data. 


\section{Background}

The burden of non-communicable diseases (NCDs) and associated risk factors are major health challenges of the twenty-first century [1]. Among the most important modifiable risk factors for developing NCDs are overweight and obesity [1]. Behavioural change interventions which focus on promoting healthy dietary and physical activity behaviours can be effective in achieving weight loss [2]. However, these interventions are often most effective among people with a high socioeconomic position (SEP) [3] compared to those with a low SEP, whereas obesity and unhealthy lifestyle behaviours are mostly observed among people with a low SEP [4, 5]. These behaviours are found to substantially contribute to socioeconomic health inequities [6].

The relationship between lifestyle behaviours such as eating behaviour, on the one hand, and health, overweight, obesity and the prevalence of NCDs on the other is well established [7-9]. Eating behaviour is complex and can be influenced by a wide range of factors [10]. One important factor is the food environment, which currently promotes the consumption of energy-dense, nutrient-poor foods [11]. The extent to which people are capable of making healthy food choices in this environment is covered by the concept of food literacy. Food literacy can be described as the interconnected knowledge, skills and behaviours which are essential for planning, managing, selecting, preparing and eating foods in order to meet needs and determine food intake [12]. Additional to this individual perspective, recent attempts have been made to more comprehensively define food literacy by including the role of food systems on access and adherence to healthy eating [13]. Furthermore, a wide range of research describes the conceptual association between food literacy and health, well-being and nutrition behaviour [12, 14-19]. To the contrary, the empirical association between food literacy and diet is limited [20]. Similarly, the association between food literacy, individual and collective well-being has not been researched extensively yet $[15,20]$. However, the limited existing evidence suggests that higher levels of food literacy may be associated with healthier food consumption [21] and that improving food literacy behaviours may lead to higher diet quality [22].

Food literacy is a specific form of the broader concept of health literacy [17], defined by Sørensen et al. (2012) as 'people's knowledge, motivation and competences to access, understand, appraise and apply health information in order to make judgments and take decisions in everyday life concerning healthcare, disease prevention and health promotion to maintain and improve quality of life throughout the life course' [23]. Low health literacy levels have been found to be associated with negative health outcomes such as increased overall mortality [24], less use of preventive services [25], and increased body mass index (BMI), overweight and obesity [26]. In Europe, $47.6 \%$ of the population show inadequate or problematic levels of health literacy [27]. In the Netherlands, these inadequate or problematic levels are found in more than one in three adults (36.4\%) [28].

Health literacy levels have regularly been reported to be unequally distributed throughout society. Regarding gender, the evidence for the association with health literacy is inconsistent. Some studies show that the level of health literacy in women is to a certain extent higher than in men [29-33] although others show no differences [34, 35]. Evidence for the role of age in predicting health literacy seems to be consistent, with older age associated with low health literacy levels [36-38]. However, there might be differences in the direction of this role between health literacy dimensions [31]. Regarding socioeconomic differences, people with a low SEP often show lower levels of health literacy compared to people with a high SEP [39]. Understanding and measuring health literacy levels is important when considering the prevention of chronic diseases [40] because these levels are strongly related to health and well-being [24, 26]. Specifically, the domains of health promotion and disease prevention within the concept of health literacy [23] are expected to provide valuable insights into health promotion activities in a prevention context. In this study, these domains will be collectively referred to as 'health promotion literacy'.

As food literacy is closely linked to health literacy [17] and people with a low SEP tend to consume lower-quality diets compared to people with a high SEP [5], we hypothesize that people with a low level of education will also have lower levels of food literacy in line with observed socioeconomic gradients in health literacy [26, 39]. Furthermore, there is a lack of knowledge regarding the empirical association between food literacy and health literacy as stated before. Although the concepts of food literacy and health literacy are closely linked [17], theoretical differences exist. Health literacy has a relatively greater focus on health information [23], while food literacy is described relatively more commonly in terms of skills and behaviour [12]. Therefore, determining whether and to what extent the association between food and health literacy exists empirically will add to our understanding of the way in which health promotion activities should be directed.

This study aims to determine the level of selfperceived food literacy and health promotion literacy among adults with a low and medium level of education and from various subgroups (i.e. based on gender, age, level of education and BMI), as well as the association between these levels. Furthermore, it explores the associations between self-perceived food literacy and health promotion literacy in BMI. 


\section{Methods}

\section{Design, study population and recruitment}

The workplace was chosen as the setting for this crosssectional study because it is part of a research project which aims to influence the behaviour and environments of people with a low and medium level of education. Inclusion criteria for the study population were being 18 or older, being employed, living in the Netherlands, understanding the Dutch language at a sufficient level and having a low or medium level of education (i.e. with secondary vocational education as the highest level of education).

Regarding recruitment, job sectors which mainly employ people with a low and medium level of education [41] were selected first. Second, companies throughout these job sectors were selected by means of purposive sampling. A list was made of companies across the Netherlands which were expected to employ at least 30 persons with a low or medium level of education. Third, 124 companies throughout 9 of the 12 provinces of the Netherlands were emailed an invitation to participate in this study. If they did not answer, the researcher (HS) called them within a week to explain the study in more detail and to invite them to participate. Twenty companies responded that they were not willing to participate for several reasons (e.g. corporate reorganization processes, involvement in other studies, workload or no interest in preventive health). Eighty-nine companies did not elaborate on their reasons for non-participation or could not be reached. The contact persons (e.g. employers or human resource managers) of fifteen companies which were interested in participating were contacted by telephone. Eight companies in a variety of job sectors - civil engineering $(n=1)$, healthcare $(n=3)$, construction $(n=1)$, public sector $(n=1)$, infrastructure $(n=1)$ and logistics $(n=1)$ - were ultimately willing to participate. The contact persons of these eight companies approached their employees based on the inclusion criteria and by using flyers provided by the researcher (HS).

\section{Data collection and procedure}

Data were collected using a questionnaire that was filled in by participants at their workplace. First, the questionnaire was pilot-tested among a small convenience sample of employees with a low level of education $(n=4)$ in a real-life work setting. The researcher asked the questions and the employee answered according to the 'thinking aloud' method [42]. Their insights suggested that the items of the health literacy scales should be shortened and their comprehensibility improved. Therefore, a Dutch linguistic company, also involved in the development of the Self-Perceived Food Literacy Scale (SPFLS) [21], converted the health promotion literacy items to 'B1' language level, a level that is generally understood by $95 \%$ of people [43]. This adaptation was made in consultation with the researcher to retain the items' connotations.

Participants filled in the questionnaire either in an individual setting or in a group setting due to practical reasons (e.g. time constraints set by the employer and the employees' type of job). In the individual setting, participants completed the questionnaire in a private room using a computer assisted modality while the researcher (HS) was present. Participants who had difficulty reading were able to indicate their preference for the researcher to read the questions aloud. In the group setting, participants completed the questionnaire using a paper and pencil modality while the researcher (HS) and other participants were present in the same room. All participants provided written informed consent. Questionnaire completion took 15 to $30 \mathrm{~min}$. Participants were compensated with a healthy snack.

\section{Measurements \\ Self-perceived food literacy scale}

The Self-Perceived Food Literacy Scale (SPFLS) is a validated, theory-driven, expert-based instrument which measures self-perceived food literacy (SPFL) with respect to healthy eating among adults, using B1 language level [21]. The overall scale shows good reliability (Cronbach's $\alpha=0.83$ ) and is comparable to the reliability found in our sample (Cronbach's $\alpha=0.84$ ). Furthermore, convergent, divergent and criterion validity have been indicated [21]. The SPFLS consisted of 29 items with five-point Likert answering scales (from $1=$ 'No, never' to $5=$ 'Yes, always'). A higher mean SPFL score indicated a higher level of SPFL [21]. The items covered the following eight subscales: Food Preparation Skills (e.g. 'Are you able to alter a recipe yourself?'), Resilience and Resistance (e.g. 'Are you able to eat healthily when you feel stressed?'), Healthy Snack Styles (e.g. 'Do you eat fruit as a snack?'), Social and Conscious Eating (e.g. 'Do you find it important to eat dinner at the same time if you are with others?'), Examining Food Labels (e.g. 'Do you check the nutritional labels of products for calories, fat, sugar or salt content?'), Daily Food Planning (e.g. 'If you have something to eat, do you take account of what you will eat later that day?'), Healthy Budgeting (e.g. 'Do you purchase healthy foods, even if they are a bit more expensive?') and Healthy Food Stockpiling (e.g. 'Do you have 4 or more bottles of sugar-sweetened beverages or lemonade containing sugar in stock?'). These subscales corresponded to the variables used in the analyses of this study. Items which required reversed scoring were recoded. No cut-off point for missing values was described by the SPFLS developers [21] and therefore only 
cases without missing values were used to calculate mean SPFL.

In order to interpret mean SPFL levels, mean SPFL was divided into the two categories low (1.00-3.49) and high (3.50-5.00). The connotation of the response option 3.00 = 'Sometimes I do, sometimes I do not' arguably does not represent having a high level of SPFL while the option $4.00=$ 'Yes, most of the time' does. Therefore, the cutoff point of 3.49 in the middle of those response options was chosen. This procedure was also conducted in a German study, to our knowledge the first and only study that applied the SPFLS to a general population including people with a low level of education [44].

\section{Health promotion literacy}

Since our study was conducted within the context of prevention and health promotion, we used the subscales 'Health Promotion' and 'Disease prevention' of the short European Health Literacy Survey Questionnaire (HLSEU-Q16) $[45,46]$ in Dutch to measure 'health promotion literacy' (HPL). We used the items of the HLS-EUQ16 subscales instead of the original HLS-EU-Q47 [45] for pragmatic reasons (e.g. to make sure that the completion time of the total questionnaire would be feasible). The HPL scale (HPLS) showed good reliability (Cronbach's $\alpha=0.83$ ). Convergent validity was indicated by a positive correlation $(r=.25, P<.001, n=203)$ between the HPLS and SPFLS. Furthermore, face validity was indicated by a thorough review process of the maintenance of the items' connotations after conversion to B1 language level, by the first author and three of the co-authors.

The subscale of Health Promotion measures the ability to access, understand and process information on determinants of health in the social and physical environment. This subscale was composed of four items (e.g. If family or friends give you advice about health, do you understand that advice?'), which were answered on a four-point Likert scale (from $1=$ 'No, very poorly' to $4=$ 'Yes, very well'). The subscale of Disease Prevention assesses the ability to access, understand, process and apply information on risk factors for health. This subscale was composed of five items (e.g. 'Do you understand information about unhealthy behaviour? For example about smoking, physical activity or drinking alcohol?'), which were answered on a four-point Likert scale (from $1=$ 'No, I understand it very poorly' to $4=$ 'Yes, I understand it very well'). The answer option 'I don't know' was not used as it is only used when administered orally by an interviewer [45].

Mean HPL was calculated based on the nine items of both subscales. Furthermore, HPL categories were calculated. The principles of the sum scoring procedure of the HLS-EU-Q16 [46] from which the HPL items were derived, were applied to calculate HPL categories. First, each item was dichotomized by scoring the answer options 1 and 2 ('Very difficult' and 'Difficult') as 0 and the answer options 3 and 4 ('Easy' and 'Very easy') as 1. Subsequently, this resulted in a sum score ranging from 0 to 9. In line with the HLS-EU-Q scoring procedures in which a health literacy score can only be computed for respondents who answered at least $80 \%$ of the items [27, 46], only respondents who completed at least 8 out of 9 items were considered. Cut-off points were based on the distribution of sum scores in the HLS-EU-Q16 categories. The sum score ranges from 0 to 16 in the HLS-EUQ16, of which $50 \%$ is attributed to the category inadequate $(0-8), 25 \%$ to the category problematic [9-12] and $25 \%$ to the category sufficient $[13-16,46]$. This distribution was applied to the HPL sum score ranging between 0 and 9, which resulted in the three HPL categories inadequate $(0-5)$, problematic $[6,7]$ and sufficient $[8,9]$.

\section{Characteristics of participants regarding demographics and BMI}

Demographic information was obtained from each participant concerning gender, age and highest level of education. Furthermore, self-reported height (centimetres when not wearing shoes) and self-reported weight (kilograms) were obtained. BMI was calculated by dividing the weight in kilograms by the square of the height in meters. Furthermore, it was divided in three weightstatus categories: Healthy weight (18.50-24.99), overweight (25-29.99) and obese ( $\geq 30.0)$.

\section{Level of education}

Level of education was divided into two levels according to the Dutch standard classification of education [47]: low (those whose highest level of education was that of secondary vocational education level 1) and medium (those whose highest level of education was that of secondary vocational education level 4).

\section{Data analyses}

Data were analysed in SPSS Statistics 26.0. The presence of outliers among the main variables was tested. One outlier on BMI was found and subsequently converted to missing data. Furthermore, one BMI value was below the healthy weight range (i.e. $<18.5 \mathrm{~kg} / \mathrm{m}^{2}[48]$ ). This value was converted to missing data as $n=1$ was not sufficient to make it a separate category. Missing values (i.e. 19 for SPFL and 2 for HPL) were left as 'missing' without excluding cases.

The sample was described by performing descriptive analyses. The mean values for SPFL, HPL, and their subscales as well as the distribution across categories were calculated using descriptive analyses. Analyses of variance 
(ANOVA) were performed to test the difference in mean SPFL and HPL between the subgroups gender, age, level of education and BMI. First, assumptions for normality were assessed and met. A Tukey's post hoc test was used to pairwise compare the three BMI categories. Accordingly, significant between-group differences were explored. The correlations between SPFL, HPL and the subscales were computed by the Pearson's correlation test. A significance level of 0.05 was used (2-sided). Pearson's correlation coefficients were interpreted as small $(\geq .10 r<.30)$, moderate $(\geq .30 r<.50)$ or large $(r \geq .50)$ [49]. The association between SPFL and HPL was explored by multivariate linear regression analyses, with SPFL as outcome variable and demographic characteristics as covariates (i.e. gender, age and level of education). The assumptions were tested and met. No statistically significant interaction between demographic characteristics and HPL was found, hence analyses were not stratified. The relationships between SPFL and HPL in BMI respectively were also explored using multivariate linear regression analyses. First, assumptions were tested and met. BMI was the outcome variable. Subsequently, adjustments for demographic characteristics (i.e. gender, age and level of education) as covariates were applied. No statistically significant interaction between demographic characteristics and either HPL nor SPFL were found, hence analyses were not stratified.

\section{Results}

In total, 222 participants met our inclusion criteria. As shown in Table 1, the majority of the sample were men $(61.1 \%)$ and aged 40 or older $(60.2 \%)$.

\section{Descriptive and univariate analyses}

Mean SPFL and the distribution over low and high levels can be found in Table 1. SPFL was highest for the Healthy Budgeting subscale $(3.96 \pm .77)$ and lowest for the Examining Food Labels subscale $(2.27 \pm 1.19)$ (Table 2). The scores on the overall SPFL scale and on seven out of the eight SPFL subscales were significantly higher amongst women than men. To illustrate, on the subscale Food Preparation Skills the mean for women was $3.91(S D=.69)$ and 3.57 for men $(S D=.83)(F(1$, $211)=3.07, P=.002)$. Solely the scores on the Examining Food Labels subscale did not differ between men and women $(F(1,216)=3.07, P=.081)$. The overall level of SPFL was significantly higher among participants aged 40 or older than among participants aged under 40 ( $F$ $(1,195)=11.63, \quad P=.001)$. Significantly higher mean scores were found among participants aged 40 or older on the Daily Food Planning $(F(1,213)=5.67, P=.018)$, Social and Conscious Eating $(F(1,211)=20.00, P=$ $<.001)$, and Resilience and Resistance $(F(1,205)=10.33$, $P=.002)$ subscales. No significant differences were found
Table 1 Characteristics of participants including demographics, BMI, SPFL levels and HPL levels

\begin{tabular}{|c|c|c|c|c|}
\hline Characteristic & $n$ & & Subgroup & $n(\%)$ \\
\hline \multirow[t]{3}{*}{ Gender } & 221 & & & \\
\hline & & & Men & $135(61.1 \%)$ \\
\hline & & & Women & 86 (38.9\%) \\
\hline \multirow[t]{3}{*}{ Age $(M \pm S D)$} & 216 & $42.6 \pm 13.0$ & & \\
\hline & & & $<40$ years & 86 (39.8\%) \\
\hline & & & $\geq 40$ years & $130(60.2 \%)$ \\
\hline \multirow[t]{3}{*}{ Level of education } & 222 & & & \\
\hline & & & Low & 109 (49.1\%) \\
\hline & & & Medium & 113 (50.9\%) \\
\hline $\mathrm{BMI}(\mathrm{M} \pm \mathrm{SD})$ & 211 & $25.9 \pm 4.3$ & & \\
\hline \multirow[t]{3}{*}{ Weight-status } & & & Healthy weight & $94(44.5 \%)$ \\
\hline & & & Overweight & $80(37.9 \%)$ \\
\hline & & & Obese & $37(17.5 \%)$ \\
\hline SPFL $(M \pm S D)$ & 203 & $3.37 \pm .47$ & & \\
\hline \multirow[t]{3}{*}{ Range } & & $1.00-5.00$ & & \\
\hline & & & Low & $128(63.1 \%)$ \\
\hline & & & High & 75 (36.9\%) \\
\hline $\mathrm{HPL}(M \pm S D)$ & 220 & $3.11 \pm .40$ & & \\
\hline \multirow[t]{4}{*}{ Range } & & $1.00-4.00$ & & \\
\hline & & & Inadequate & $21(9.5 \%)$ \\
\hline & & & Problematic & $55(25 \%)$ \\
\hline & & & Sufficient & $144(65.4 \%)$ \\
\hline
\end{tabular}

between participants with a low or medium level of education regarding mean SPFL $(F(1,201)=.021, P=.885)$ or subscales. Similarly, no significant differences were found between the weight-status categories regarding mean SPFL $(F(2,191)=.73, P=.484)$ or subscales.

Mean HPL and the distribution over inadequate, problematic and sufficient can be found in Table 1. Women scored significantly higher than men on the Disease Prevention subscale $(F(1,213)=5.39, P=.021)$ (Table 2$)$. Participants aged 40 or older scored significantly higher on HPL $(F(1,212)=6.85, P=.010)$ and the Disease Prevention subscale $(F(1,208)=9.52, P=.002)$ than participants under the age of 40 . No significant difference was found between participants with a low level of education and participants with a medium level of education regarding mean HPL $(F(1,218)=.157, P=.693)$ or subscales. Regarding HPL and weight-status, a significant difference was found for the Disease Prevention subscale (F $(2,204)=3.87, P=.022)$. A Tukey's post hoc test showed that participants with obesity scored significantly higher on the Disease Prevention subscale than participants in the overweight subgroup $(P=.016)$. There was no significant difference between participants with a healthy weight and participants with overweight $(P=$ 
Table 2 Comparison between subgroups with respect to SPFL and HPL levels

\begin{tabular}{|c|c|c|c|c|c|c|c|c|c|c|c|c|c|c|}
\hline \multirow[t]{3}{*}{ 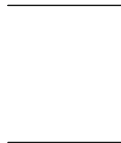 } & \multirow[t]{3}{*}{ Total } & \multirow{2}{*}{\multicolumn{2}{|c|}{ Gender $(n=221)$}} & & & & & & & & & & & \\
\hline & & & & & \multicolumn{2}{|c|}{ Age $(n=216)$} & & \multicolumn{2}{|c|}{ Education $(n=222)$} & & \multicolumn{4}{|c|}{$\mathrm{BMI}(n=211)$} \\
\hline & & Men & Women & & $<40$ years & $\geq 40$ years & & Low & Medium & & Healthy & Overweight & Obese & \\
\hline \multicolumn{15}{|l|}{ 1. SPFL } \\
\hline M & 3.37 & 3.26 & 3.57 & & 3.25 & 3.47 & & 3.37 & 3.38 & & 3.36 & 3.34 & 3.46 & \\
\hline$S D$ & .47 & .42 & .49 & & .50 & .43 & & .46 & .48 & & .48 & .45 & .51 & \\
\hline P-value & & & & $<.001$ & & & .001 & & & .885 & & & & .484 \\
\hline \multicolumn{15}{|c|}{ 1a. Examining Food Labels } \\
\hline M & 2.27 & 2.16 & 2.45 & & 2.19 & 2.34 & & 2.20 & 2.33 & & 2.17 & 2.33 & 2.55 & \\
\hline$S D$ & 1.19 & 1.11 & 1.30 & & 1.18 & 1.20 & & 1.15 & 1.23 & & 1.19 & 1.15 & 1.25 & \\
\hline$P$-value & & & & .081 & & & .364 & & & .423 & & & & .239 \\
\hline \multicolumn{15}{|c|}{ 1b. Food Preparation Skills } \\
\hline M & 3.70 & 3.57 & 3.91 & & 3.61 & 3.80 & & 3.60 & 3.78 & & 3.82 & 3.57 & 3.65 & \\
\hline$S D$ & .80 & .83 & .69 & & .86 & .71 & & .73 & .84 & & .77 & .81 & .81 & \\
\hline P-value & & & & .002 & & & .082 & & & .094 & & & & .112 \\
\hline \multicolumn{15}{|c|}{ 1c. Healthy Food Stockpiling } \\
\hline M & 2.97 & 2.85 & 3.21 & & 2.80 & 3.11 & & 2.94 & 3.00 & & 2.90 & 2.98 & 3.19 & \\
\hline$S D$ & 1.11 & 1.06 & 1.13 & & 1.14 & 1.07 & & 1.03 & 1.18 & & 1.18 & 1.02 & 1.15 & \\
\hline P-value & & & & .018 & & & .051 & & & .688 & & & & .417 \\
\hline \multicolumn{15}{|c|}{ 1d. Daily Food Planning } \\
\hline M & 3.01 & 2.89 & 3.23 & & 2.80 & 3.16 & & 3.06 & 2.96 & & 2.89 & 3.15 & 3.09 & \\
\hline$S D$ & 1.10 & 1.06 & 1.12 & & 1.19 & 1.02 & & 1.05 & 1.14 & & 1.14 & 1.00 & 1.10 & \\
\hline$P$-value & & & & .024 & & & .018 & & & .519 & & & & .272 \\
\hline \multicolumn{15}{|c|}{ 1e. Healthy Budgeting } \\
\hline M & 3.96 & 3.85 & 4.14 & & 3.85 & 4.04 & & 3.93 & 3.98 & & 3.94 & 3.92 & 4.12 & \\
\hline$S D$ & .77 & .83 & .61 & & .82 & .73 & & .81 & .73 & & .72 & .76 & .90 & \\
\hline$P$-value & & & & .005 & & & .077 & & & .677 & & & & .396 \\
\hline \multicolumn{15}{|c|}{$1 \mathrm{f}$. Social and Conscious Eating } \\
\hline M & 3.85 & 3.72 & 4.04 & & 3.54 & 4.03 & & 3.88 & 3.82 & & 3.70 & 3.93 & 4.02 & \\
\hline$S D$ & .82 & .85 & .73 & & .87 & .72 & & .83 & .81 & & .91 & .69 & .85 & \\
\hline P-value & & & & .005 & & & $<.001$ & & & .589 & & & & .077 \\
\hline \multicolumn{15}{|c|}{$1 \mathrm{~g}$. Resilience and Resistance } \\
\hline M & 3.60 & 3.52 & 3.72 & & 3.43 & 3.70 & & 3.64 & 3.56 & & 3.60 & 3.59 & 3.58 & \\
\hline$S D$ & .61 & .58 & .65 & & .65 & .57 & & .62 & .60 & & .68 & .57 & .55 & \\
\hline P-value & & & & .018 & & & .002 & & & .370 & & & & .985 \\
\hline \multicolumn{15}{|c|}{1 h. Healthy Snack Styles } \\
\hline M & 3.14 & 3.04 & 3.33 & & 3.16 & 3.16 & & 3.11 & 3.18 & & 3.14 & 3.06 & 3.24 & \\
\hline$S D$ & .83 & .85 & .77 & & .81 & .86 & & .83 & .84 & & .85 & .79 & .87 & \\
\hline P-value & & & & .013 & & & .977 & & & .545 & & & & .512 \\
\hline \multicolumn{15}{|l|}{ 2. HPL } \\
\hline M & 3.11 & 3.08 & 3.15 & & 3.02 & 3.17 & & 3.12 & 3.10 & & 3.14 & 3.06 & 3.19 & \\
\hline$S D$ & .40 & .41 & .38 & & .42 & .38 & & .38 & .42 & & .37 & .48 & .33 & \\
\hline$P$-value & & & & .182 & & & .010 & & & .693 & & & & .237 \\
\hline
\end{tabular}


Table 2 Comparison between subgroups with respect to SPFL and HPL levels (Continued)

\begin{tabular}{|c|c|c|c|c|c|c|c|c|c|c|c|c|c|c|}
\hline \multirow[t]{3}{*}{ 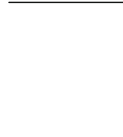 } & \multirow[t]{3}{*}{ Total } & \multirow{2}{*}{\multicolumn{2}{|c|}{ Gender $(n=221)$}} & & \multirow{2}{*}{\multicolumn{2}{|c|}{ Age $(n=216)$}} & & & & & & & & \\
\hline & & & & & & & & \multicolumn{2}{|c|}{ Education $(n=222)$} & & \multicolumn{4}{|c|}{ BMI $(n=211)$} \\
\hline & & Men & Women & & $<40$ years & $\geq 40$ years & & Low & Medium & & Healthy & Overweight & Obese & \\
\hline \multicolumn{15}{|c|}{ 2a. Health Promotion } \\
\hline M & 3.10 & 3.10 & 3.10 & & 3.05 & 3.14 & & 3.08 & 3.13 & & 3.16 & 3.07 & 3.08 & \\
\hline$S D$ & .44 & .44 & .44 & & .50 & .40 & & .42 & .46 & & .42 & .50 & .41 & \\
\hline P-value & & & & .893 & & & .183 & & & .456 & & & & .427 \\
\hline \multicolumn{15}{|c|}{ 2b. Disease Prevention } \\
\hline M & 3.12 & 3.07 & 3.20 & & 3.01 & 3.19 & & 3.16 & 3.08 & & 3.12 & 3.05 & 3.29 & \\
\hline$S D$ & & .45 & .39 & & .43 & .42 & & .42 & .44 & & .38 & .51 & .35 & \\
\hline$P$-value & & & & .021 & & & .002 & & & .180 & & & & .022 \\
\hline
\end{tabular}

.568) or between participants with a healthy weight and obesity $(P=.103)$.

\section{The association between SPFL and HPL}

Pearson's $\mathrm{r}$ indicated a small positive correlation between SPFL and HPL, $r=.25, P<.001(n=203)$. A small positive correlation was also found between SPFL and the Health Promotion subscale of HPL, $r=.24, P=.001$ $(n=201)$. Likewise, a small positive correlation was found between SPFL and the Disease Prevention subscale of HPL, $r=.23, P=.001 \quad(n=201)$. Furthermore, multivariate linear regression analyses showed a significant association between SPFL and HPL $(B=.31,95 \%$ $\mathrm{CI}=.15-.48)$, after adjusting for the covariates gender, age and level of education (Table 3). This indicated that on average an increase of one point in HPL corresponded to an increase in SPFL of .31 points.

\section{Multivariate analyses for BMI}

Multivariate linear regression analyses showed no significant associations between SPFL and HPL in BMI, after adjusting for the covariates gender, age and level of education (Table 4).

\section{Discussion}

The aim of this study was to determine the levels of selfperceived food literacy (SPFL) and health promotion literacy (HPL) among adults with a low and medium level of education and from various demographic subgroups, as well as the association between these levels. Furthermore, it aimed to explore the relationship between SPFL and HPL in BMI. The results indicate that most adults in our sample had a low level of SPFL and that a third had inadequate or problematic HPL levels.

We observed that women scored higher on the majority of the SPFL subscales compared to men. In terms of age, participants aged 40 or older scored significantly higher on SPFL and HPL than participants aged under 40. We found no educational or weight-status differences in the mean values of the overall SPFL scale and its subscales. Likewise, no educational difference was found for HPL. Regarding the Disease Prevention subscale of HPL, participants with obesity scored significantly higher than participants with overweight. The association between SPFL and HPL was positive, though small and also present after adjusting for gender, age and level of education. Finally, no relationships were found between SPFL and HPL in BMI.

We observed that women on average had higher SPFL compared to men, except for the subscale 'Examining Food Labels'. Comparable differences were observed in prior research suggesting that women have a healthier diet than men [50] and a healthier diet appears to be related to higher levels of food literacy [21]. Furthermore, women have been found to spend more time cooking than men [51, 52]. Additionally, women appear to be more involved in weight control and to have stronger beliefs about healthy food consumption compared to men [53]. Therefore, women may be more engaged in acquiring knowledge and skills related to healthy eating. These findings may explain the gender differences observed in the SPFL levels in our sample.

Regarding age, we found positive associations with higher SPFL and HPL while other studies seem to

Table 3 Linear regression model for SPFL as dependent variable and HPL as independent variable

\begin{tabular}{|c|c|c|c|c|c|c|c|}
\hline & \multicolumn{2}{|c|}{ Unstandardized Coefficients } & \multirow{2}{*}{$\begin{array}{l}\text { Standardized Coefficients } \\
\text { Beta }\end{array}$} & \multirow[b]{2}{*}{$\mathbf{t}$} & \multirow[b]{2}{*}{ Sig. } & \multicolumn{2}{|c|}{$\mathbf{9 5 \%}$ confidence interval for B } \\
\hline & B & Std. Error & & & & Lower Bound & Upper Bound \\
\hline $\mathrm{HPL}$ & .31 & .08 & .25 & 3.73 & $<.001$ & .15 & .48 \\
\hline
\end{tabular}

Note: SPFL and HPL are presented after adjusting for the covariates gender, age and level of education 
Table 4 Linear regression model for BMI as dependent variable, SPFL and HPL as independent variables

\begin{tabular}{|c|c|c|c|c|c|c|c|}
\hline & \multicolumn{2}{|c|}{ Unstandardized Coefficients } & \multirow{2}{*}{$\begin{array}{l}\text { Standardized Coefficients } \\
\text { Beta }\end{array}$} & \multirow[b]{2}{*}{ t } & \multirow[b]{2}{*}{ Sig. } & \multicolumn{2}{|c|}{$95 \%$ confidence interval for B } \\
\hline & B & Std. Error & & & & Lower Bound & Upper Bound \\
\hline SPFL & .45 & .66 & .05 & .69 & .494 & -.85 & 1.76 \\
\hline HPL & .17 & .73 & .02 & .23 & .815 & -1.28 & 1.62 \\
\hline
\end{tabular}

Note: SPFL and HPL are presented after adjusting for the covariates gender, age and level of education

consistently find opposite results for health literacy [3638]. However, earlier research suggests that the direction of this association may vary between health literacy dimensions [31]. Therefore, our findings for HPL may be explained by the fact that it solely covers two domains of health literacy (i.e. health promotion and disease prevention) which seem to increase with age in our sample.

We found no differences in the mean values of SPFL, HPL and their subscales between adults with a low and medium level of education, though we expected to find an educational difference in SPFL and HPL based on previous studies in food literacy and health literacy [29, 34, 39]. However, these previous studies often compared low with high levels of education and operationalized the factor of level of education differently. We would suggest that the absence of an educational difference in our sample indicates that our sample does not differ in SPFL and HPL levels based on having a low or medium level of education.

The correlation between SPFL and HPL was positive, though small. Earlier research also indicated a positive association between food literacy and health literacy [15]. Moreover, the association between SPFL and HPL was still significant after adjusting for gender, age and level of education though it remained rather small. Our findings indicate that improving SPFL or HPL does not necessarily imply that the other concept will improve to the same extent. Therefore, health promotion activities such as lifestyle interventions which focus on stimulating healthy dietary behaviour among adults with a low and medium level of education should consider paying attention to both concepts. It furthermore suggests that SPFL and HPL are positively related in an empirical way, in addition to the theoretical association. Additionally, the results suggests that the relationship between SPFL and HPL exists independently of the demographic characteristics observed in our sample.

Furthermore, the absence of associations between SPFL and HPL in BMI was unexpected. The absence of weight-status differences in our sample may be explained by the fact that BMI can be influenced by a broad variety of factors. Our SPFL and HPL measures may not have been comprehensive and direct enough to indicate an association. Low health literacy has in fact been linked to an increased BMI in earlier research [26, 54]. SPFL has been previously linked to healthier food consumption [21] but not directly to BMI, factors such as vegetable intake [55] and fast food consumption [56] have been linked to BMI. Therefore, the inclusion of more direct proxies of SPFL such as food intake might have indicate BMI differences. More comprehensive and direct factors should therefore be explored when aiming to understand the role of food and health literacy in BMI.

One limitation of this study was that the purposive sampling method might have induced selection bias as companies' contact persons who agreed to participate, might have already been engaged in health promotion activities for their employees. In addition, employees completed the questionnaire at their workplace in a setting in which the researcher was present. This might have induced social desirability. However, this presence also assured comprehensibility about the aim and content of the questionnaire. Another limitation was that the original SPFLS was validated in a sample with an above-average rather than a below-average level of education compared to the general Dutch population. Regarding the Health Promotion and Disease Prevention subscales of HPL, no validation in Dutch has been performed yet. However, both the SPFLS [21] as well as the HPL subscales were used after conversion to B1 language level and are therefore expected to be suitable for people with a low and medium level of education. Finally, a recent study concluded that combining selfreporting and objective measures for understanding health literacy could contribute to understanding health literacy more broadly [57]. Therefore, the self-reporting nature of SPFL and HPL should be noted. SPFL and HPL levels describe the participants' ideas about their eating and health behaviours rather than their objective behaviours. Although these results are valuable in the broader understanding of food and health literacy, the generalizability of the findings is unknown and should therefore be interpreted cautiously.

One strength of this study was that we derived two subscales to measure HPL from the HLS-EU-Q16, which is expected to be suitable for determining health literacy in populations with limited literacy [58]. Therefore, we expect that the two measured subscales derived from the HLS-EU-Q16 were appropriate for our sample. Another strength was that we simplified these items to B1 language level and that certain items were provided with 
explanatory text, as is recommended for use within groups who are expected to show limited literacy levels [58]. Finally, the majority of the sample were men $(61.6 \%)$, which is a strength as men are often underrepresented in research regarding food literacy aspects such as food purchase and cooking [59].

\section{Recommendations}

Our results suggest that there is room for improvement in both SPFL and HPL levels among adults with a low and medium level of education, because the majority of our sample had a low SPFL level and a third had inadequate or problematic HPL levels. A contribution to this improvement can be made by addressing causal determinants of health literacy. General literacy is one of the best indicators of health literacy $[60,61]$ and therefore adapting health information to the general literacy levels (i.e. reading and writing) of this group may be a step towards this improvement.

Future research should consider exploring differences in food and health literacy between adults with a low and medium level of education on the one hand and adults with a high level of education on the other hand. Comparing low and medium educated groups with high educated groups might add to our understanding of socioeconomic trends in food and health literacy. Subsequently, it might contribute to our knowledge of ways to reduce socioeconomic health inequities. Furthermore, it is recommended to consider food and health literacy in health promotion activities not only for groups with a low but also with a medium level of education.

Another direction of future research is to further explore the relationship between food literacy, health literacy and BMI. Based on this study, it is recommended to investigate food and health literacy in ways that more directly influence BMI. This might provide us with a better understanding of the role of food and health literacy in weight-status.

\section{Conclusions}

In conclusion, the majority of our sample scored low on SPFL and a third scored inadequate or problematic on HPL. Regarding subgroups, women scored higher on the majority of the SPFL subscales (7 out of 8) compared to men. No differences in SPFL or HPL were found between groups with a low and medium level of education. In addition, SPFL and HPL were shown to be positively associated, to a small extent. HPL was associated with SPFL after adjusting for demographic characteristics. No relationships were found between SPFL and HPL in BMI. Regarding future research, the comparison of low and middle SEP groups with high SEP groups when exploring food and health literacy levels should be considered. Additionally, future research should explore more direct proxies of weightstatus to better understand the role of health and food literacy in overweight patterns.

\section{Abbreviations}

ANOVA: Analyses of variance; BMl: Body mass index; HPL: Health promotion literacy; HLS-EU-Q: European Health Literacy Survey Questionnaire; HLS-EUQ16: Short European Health Literacy Survey Questionnaire-16; HLS-EUQ47: European Health Literacy Survey Questionnaire-47; NCDs: Noncommunicable diseases; SEP: Socioeconomic position; SPFL: Self-perceived food literacy; SPFLS: Self-Perceived Food Literacy Scale

\section{Acknowledgements}

We would like to thank all the participants for their time and willingness to contribute to this study. We would also like to thank the employers who made the data collection within their companies possible. Furthermore, we would like to thank the SMARTsize@Work project team for their contribution to the recruitment process. Ultimately, we would like to thank Bureau Taal for translating the HPL items to B1 language level.

\section{Authors' contributions}

WK, CR and IS conceived the study. HS was the executive researcher of the study, supported by WK, CR and IS. MP contributed to the interpretation of the SPFL results. HS conducted the analyses and drafted the manuscript with a major contribution of WK. WK, MP, CR, KB and IS provided feedback. All authors read and approved the final manuscript.

\section{Funding}

This study was funded by the Netherlands Organisation for Health Research and Development (ZonMw, Grant Number 50-53115-98-004). ZonMw was involved in the design of the study. ZonMw was not involved in the data collection, analysis, interpretation or in writing the manuscript.

\section{Availability of data and materials}

The datasets used and/or analysed during the current study are available from the corresponding author on reasonable request.

\section{Declarations}

\section{Ethics approval and consent to participate}

The Medical Ethical Committee of the VU University Medical Center declared that the Dutch Medical Research Involving Human Subjects Act did not apply to this study (September 4, 2018, reference code 2018.434). Therefore, no further ethics approval was required. All participants provided written informed consent.

\section{Consent for publication}

Not applicable.

\section{Competing interests}

The authors declare that they have no competing interests.

\section{Author details}

${ }^{1}$ Department of Health Sciences, Faculty of Sciences, VU University Amsterdam and Amsterdam Public Health Research Institute, $1081 \mathrm{HV}$ Amsterdam, Netherlands. ${ }^{2}$ Care for Nutrition and Health Group, School of Nursing, Christian University of Applied Sciences, 6717 JS Ede, The Netherlands. ${ }^{3}$ Chair Group Consumption and Healthy Lifestyles, Wageningen University and Research, 6700 EW Wageningen, The Netherlands. ${ }^{4}$ Institute for Physical Activity and Nutrition, Deakin University, Geelong, VIC, Australia.

Received: 2 June 2020 Accepted: 18 June 2021

Published online: 30 June 2021

\section{References}

1. World Health Organization. Global Status Report on noncommunicable diseases. Geneva: World Health Organization; 2014.

2. Sweet SN, Fortier MS. Improving physical activity and dietary behaviours with single or multiple health behaviour interventions? A synthesis of metaanalyses and reviews. Int J Environ Res Public Health. 2010;7(4):1720-43. https://doi.org/10.3390/ijerph7041720.

3. Loring B, Robertson A. Obesity and inequities: guidance for addressing inequities in overweight and obesity. Copenhagen: WHO Regional Office for Europe; 2014 
4. Cijfers over gezond gewicht in 2017. [https://www.rivm.nl/documenten/ cijfers-over-gezond-gewicht-in-2017. Accessed 29 April 2020.

5. Darmon N, Drewnowski A. Does social class predict diet quality? Am J Clin Nutr. 2008;87(5):1107-17. https://doi.org/10.1093/ajcn/87.5.1107.

6. Stringhini S, Sabia S, Shipley M, Brunner E, Nabi H, Kivimaki M, et al. Association of Socioeconomic Position with Health Behaviors and Mortality. JAMA. 2010;303(12):1159-66. https://doi.org/10.1001/jama.2010.297.

7. Yach D, Stuckler D, Brownell KD. Epidemiologic and economic consequences of the global epidemics of obesity and diabetes. Nat Med. 2006;12(1):62-6. https://doi.org/10.1038/nm0106-62.

8. Willett WC, Stampfer MJ. Current evidence on healthy eating. Annu Rev Public Health. 2013;34(1):77-95. https://doi.org/10.1146/annurev-publhealth031811-124646.

9. Micha R, Shulkin ML, Peñalvo JL, Khatibzadeh S, Singh GM, Rao M, et al. Etiologic effects and optimal intakes of foods and nutrients for risk of cardiovascular diseases and diabetes: systematic reviews and meta-analyses from the nutrition and chronic diseases expert group (NutriCoDE). PLoS One. 2017;12(4):e0175149. https://doi.org/10.1371/journal.pone.0175149.

10. Afshin A, Sur PJ, Fay KA, Cornaby L, Ferrara G, Salama JS, et al. Health effects of dietary risks in 195 countries, 1990-2017: a systematic analysis for the global burden of disease study 2017. Lancet. 2019;393(10184):1958-72. https://doi.org/10.1016/S0140-6736(19)30041-8.

11. Swinburn BA, Sacks G, Hall KD, McPherson K, Finegood DT, Moodie ML, et al. The global obesity pandemic: shaped by global drivers and local environments. Lancet. 2011;378(9793):804-14. https://doi.org/10.1016/S01406736(11)60813-1.

12. Vidgen HA, Gallegos D. Defining food literacy and its components. Appetite. 2014;76:50-9. https://doi.org/10.1016/j.appet.2014.01.010.

13. Vettori $V$, Lorini C, Milani C, Bonaccorsi G. Towards the implementation of a conceptual framework of food and nutrition literacy: providing healthy eating for the population. Int J Environ Res Public Health. 2019;16(24):5041. https://doi.org/10.3390/ijerph16245041.

14. Cullen T, Hatch J, Martin W, Higgins J, Sheppard R. Food literacy: definition and framework for action. Can J Diet Pract Res. 2015;76(3):1-6. https://doi. org/10.3148/cjdpr-2015-010.

15. Palumbo R. Sustainability of Well-being through Literacy. The Effects of Food Literacy on Sustainability of Well-being. Agriculture and Agricultural Science Procedia. 2016:8:99-106. https://doi.org/10.1016/j.aaspro.2016.02. 013.

16. Pendergast $D$, Dewhurst $Y$. Home economics and food literacy: An international investigation. Int J Home Econ. 2012;5(2):245-63.

17. Krause C, Sommerhalder K, Beer-Borst S, Abel T. Just a subtle difference? Findings from a systematic review on definitions of nutrition literacy and food literacy. Health Promot Int. 2018;33(3):378-89. https://doi.org/10.1093/ heapro/daw084.

18. Colatruglio S, Slater J. Challenges to acquiring and utilizing food literacy: Perceptions of young Canadian adults. Challenges to acquiring and utilizing food literacy: Perceptions of young Canadian adults. 2016;3:96-118. https:// doi.org/10.15353/cfs-rcea.v3i1.72.

19. Colatruglio S, Slater J. Food Literacy: Bridging the Gap between Food, Nutrition and Well-Being; 2014. p. 37-55.

20. Gréa Krause C, Beer-Borst S, Sommerhalder K, Hayoz S, Abel T. A short food literacy questionnaire (SFLQ) for adults: Findings from a Swiss validation study. Appetite. 2018;120:275-80. https://doi.org/10.1016/j.appet.2017.08.039.

21. Poelman MP, Dijkstra SC, Sponselee H, Kamphuis CB, Battjes-Fries MC, Gillebaart $M$, et al. Towards the measurement of food literacy with respect to healthy eating: the development and validation of the self perceived food literacy scale among an adult sample in the Netherlands. Int J Behav Nutr Phys Act. 2018;15(1):54. https://doi.org/10.1186/s12966-018-0687-z.

22. Begley A, Paynter E, Butcher LM, Dhaliwal SS. Effectiveness of an adult food literacy program. Nutrients. 2019;11(4):797. https://doi.org/10.3390/nu1104 0797.

23. Sørensen K, Van den Broucke S, Fullam J, Doyle G, Pelikan J, Slonska Z, et al. Health literacy and public health: a systematic review and integration of definitions and models. BMC Public Health. 2012;12(1):80. https://doi.org/1 0.1186/1471-2458-12-80

24. Baker DW, Wolf MS, Feinglass J, Thompson JA, Gazmararian JA, Huang J. Health literacy and mortality among elderly persons. JAMA Intern Med. 2007;167(14):1503-9. https://doi.org/10.1001/archinte.167.14.1503.

25. Abarca-Gómez L, Abdeen ZA, Hamid ZA, Abu-Rmeileh NM, Acosta-Cazares B, Acuin C, et al. Worldwide trends in body-mass index, underweight, overweight, and obesity from 1975 to 2016: a pooled analysis of 2416 population-based measurement studies in 128.9 million children, adolescents, and adults. Lancet. 2017;390(10113):2627-42. https://doi.org/1 0.1016/S0140-6736(17)32129-3.

26. Michou M, Panagiotakos DB, Costarelli V. Low health literacy and excess body weight: a systematic review. Cent Eur J Public Health. 2018;26(3):23441. https://doi.org/10.21101/cejph.a5172.

27. Sørensen K, Pelikan JM, Röthlin F, Ganahl K, Slonska Z, Doyle G, et al. Health literacy in Europe: comparative results of the European health literacy survey (HLS-EU). Eur J Pub Health. 2015;25(6):1053-8. https://doi.org/10.1 093/eurpub/ckv043.

28. Heijmans M, Brabers A, Rademakers J. Health literacy in Nederland. Utrecht: Nivel; 2018.

29. Clouston SAP, Manganello JA, Richards M. A life course approach to health literacy: the role of gender, educational attainment and lifetime cognitive capability. Age Ageing. 2016;46(3):493-9. https://doi.org/10.1093/ageing/a fw229.

30. Shah LC, West P, Bremmeyr K, Savoy-Moore RT. Health literacy instrument in family medicine: the "newest vital sign" ease of use and correlates. J Am Board Fam Med. 2010;23(2):195-203. https://doi.org/10.3122/jabfm.2010.02. 070278.

31. van der Heide I, Rademakers J, Schipper M, Droomers M, Sorensen K, Uiters E. Health literacy of Dutch adults: a cross sectional survey. BMC Public Health. 2013;13(1):179. https://doi.org/10.1186/1471-2458-13-179.

32. Christy SM, Gwede CK, Sutton SK, Chavarria E, Davis SN, Abdulla R, et al. Health literacy among medically underserved: the role of demographic factors, social influence, and religious beliefs. J Health Commun. 2017;22(11): 923-31. https://doi.org/10.1080/10810730.2017.1377322.

33. Lee HY, Lee J, Kim NK. Gender differences in health literacy among Korean adults: do women have a higher level of health literacy than men? Am J Mens Health. 2015;9(5):370-9. https://doi.org/10.1177/1557988314545485.

34. HLS-EU Consortium. Comparative Report of Health Literacy in Eight EU Member States. The European Health Literacy Survey HLS-EU. Vienna: Ludwig Boltzmann Institute for Health Promotion Research; 2012.

35. Jordan S, Hoebel J. Health literacy of adults in Germany: findings from the German health update (GEDA) study. Bundesgesundheitsbl Gesundheitsforsch Gesundheitsschutz. 2015;58(9):942-50. https://doi.org/1 0.1007/s00103-015-2200-z.

36. Baker DW, Gazmararian JA, Sudano J, Patterson M. The association between age and health literacy among elderly persons. J Gerontol B Psychol Sci Soc Sci. 2000;55(6):S368-74. https://doi.org/10.1093/geronb/55.6.5368.

37. Ashida S, Goodman M, Pandya C, Koehly LM, Lachance C, Stafford J, et al. Age differences in genetic knowledge, health literacy and causal beliefs for health conditions. Public Health Genomics. 2011;14(4-5):307-16. https://doi. org/10.1159/000316234.

38. Jovic-Vranes A, Bjegovic-Mikanovic V. Which women patients have better health literacy in Serbia? Patient Educ Couns. 2012;89(1):209-12. https://doi. org/10.1016/j.pec.2012.06.001.

39. Rademakers J. Kennissynthese Gezondheidsvaardigheden: Niet voor iedereen vanzelfsprekend. Utrecht: Nivel; 2014

40. Taggart J, Williams A, Dennis S, Newall A, Shortus T, Zwar N, et al. A systematic review of interventions in primary care to improve health literacy for chronic disease behavioral risk factors. BMC Fam Pract. 2012;13:49. https://doi.org/10.1186/1471-2296-13-49.

41. UWV. Kansen voor laagopgeleiden. Amsterdam: UW; 2017.

42. Ericsson KA, Simon HA. Verbal reports as data. Psychol Rev. 1980;87(3):21551. https://doi.org/10.1037/0033-295X.87.3.215.

43. Bureau Taal. Eenvoudig Nederlands. Available from: http://www.bureautaal. nl/eenvoudig-nederlands-26. [cited 2021 March 5].

44. Kolpatzik K, Zaunbrecher R. Ernährungskompetenz in Deutschland. Berlin: KomPart: 2020.

45. Sørensen K, Van den Broucke S, Pelikan JM, Fullam J, Doyle G, Slonska Z, et al. Measuring health literacy in populations: illuminating the design and development process of the European Health Literacy Survey Questionnaire (HLS-EU-Q). BMC Public Health. 2013;13:948. https://doi.org/10.1186/1471-24 58-13-948.

46. Pelikan JM, Röthlin F, Ganahl K. Measuring Comprehensive Health Literacy in General Populations: Validation of Instrument, Indices and Scales Of The HLS-EU Study. 6th Annu. Heal. Lit. Res. Conf., 2014.

47. CBS. Standaard onderwijsindeling 2016. Den Haag/Heerlen: Centraal Bureau voor de Statistiek; 2017. 
48. World Health Organization. Obesity: preventing and managing the global epidemic. Report of a WHO consultation. WHO Technical Report Series. 2000;894:1-253. PMID: 11234459.

49. Cohen LH. Life events and psychological functioning: theoretical and methodological issues: Sage Publications; 1988.

50. Silva Ml, Marques M, Carvalho C, Santos J, Conceição L, Cunha M, et al. 1225 - Sex differences in eating habits/behaviours and eating disorders symptoms, in a sample of adolescents. Eur Psychiatry. 2013;28:1.

51. Adams J, White M. Prevalence and socio-demographic correlates of time spent cooking by adults in the 2005 UK time use survey. Cross-sectional Analysis. Appetite. 2015;92:185-91. https://doi.org/10.1016/j.appet.2015.05. 022.

52. Méjean C, Si Hassen W, Gojard S, Ducrot P, Lampuré A, Brug H, et al. Social disparities in food preparation behaviours: a DEDIPAC study. Nutr J. 2017; 16(1):62. https://doi.org/10.1186/s12937-017-0281-2.

53. Wardle J, Haase A, Steptoe A, Nillapun M, Jonwutiwes K, Bellisle F. Gender differences in food choice: the contribution of health beliefs and dieting. Ann Behav Med. 2004;27(2):107-16. https://doi.org/10.1207/s15324796abm2 7025.

54. Garcia-Codina O, Juvinyà-Canal D, Amil-Bujan P, Bertran-Noguer C, González-Mestre MA, Masachs-Fatjo E, et al. Determinants of health literacy in the general population: results of the Catalan health survey. BMC Public Health. 2019;19(1):1122. https://doi.org/10.1186/s12889-019-7381-1.

55. Nour M, Lutze SA, Grech A, Allman-Farinelli M. The relationship between vegetable intake and weight outcomes: a systematic review of cohort studies. Nutrients. 2018;10(11):1626. https://doi.org/10.3390/nu10111626.

56. Cohen-Cline H, Lau R, Moudon AV, Turkheimer E, Duncan GE. Associations between fast-food consumption and body mass index: a cross-sectional study in adult twins. Twin Res Hum Genet. 2015;18(4):375-82. https://doi. org/10.1017/thg.2015.33.

57. Lorini C, Lastrucci V, Paolini D, Bonaccorsi G. Measuring health literacy combining performance-based and self-assessed measures: the roles of age, educational level and financial resources in predicting health literacy skills. A cross-sectional study conducted in Florence (Italy). BMJ Open. 2020;10(10): e035987. https://doi.org/10.1136/bmjopen-2019-035987.

58. Storms $\mathrm{H}$, Claes N, Aertgeerts B, Van den Broucke S. Measuring health literacy among low literate people: an exploratory feasibility study with the HLS-EU questionnaire. BMC Public Health. 2017;17(1):475. https://doi.org/1 0.1186/s12889-017-4391-8.

59. Thompson J, Tod A, Bissell P, Bond M. Understanding food vulnerability and health literacy in older bereaved men: a qualitative study. Health Expect. 2017;20(6):1342-9. https://doi.org/10.1111/hex.12574.

60. Yamashita T, Kunkel SR. An international comparison of the association among literacy, education, and health across the United States, Canada, Switzerland, Italy, Norway, and Bermuda: implications for health disparities. J Health Commun. 2015;20(4):406-15. https://doi.org/10.1080/10810730.2014. 977469

61. Rootman I, Ronson B. Literacy and Health Research in Canada: where have we been and where should we go? Can J Public Health. 2005;96(2):S62-77. https://doi.org/10.1007/BF03403703.

\section{Publisher's Note}

Springer Nature remains neutral with regard to jurisdictional claims in published maps and institutional affiliations.

Ready to submit your research? Choose BMC and benefit from:
- fast, convenient online submission
- thorough peer review by experienced researchers in your field
- rapid publication on acceptance
- support for research data, including large and complex data types
- gold Open Access which fosters wider collaboration and increased citations
- maximum visibility for your research: over 100M website views per year
At BMC, research is always in progress.
Learn more biomedcentral.com/submissions

